\title{
28 Research Square \\ Effects of Proton Pump Inhibitor on \\ Gastroesophageal Varices of Cirrhosis: A \\ Randomized Controlled Trial
}

\section{Xiaoning Chen}

Qilu Hospital, Shandong University

\section{Tao Zhou}

Qilu Hospital, Shandong University

Ting Zhou

Qilu Hospital, Shandong University

\section{Yueyue Li}

Qilu Hospital, Shandong University

\section{Xin Sun}

Qilu Hospital, Shandong University

\section{Baoquan Cheng}

Qilu Hospital, Shandong University

Ning Zhong

Qilu Hospital, Shandong University

\section{Xuefeng Lu}

Qilu Hospital, Shandong University

Yanjing Gao ( $\square$ gaoyanjing@sdu.edu.cn )

Qilu Hospital, Shandong University

\section{Research Article}

Keywords: Endoscopic therapy, Gastroesophageal varices, Liver cirrhosis, Proton pump inhibitor.

Posted Date: May 19th, 2021

DOI: https://doi.org/10.21203/rs.3.rs-493527/v1

License: (c) (1) This work is licensed under a Creative Commons Attribution 4.0 International License.

Read Full License 


\section{Abstract}

\section{Background}

The use of proton pump inhibitor (PPI) for gastroesophageal varices in patients with cirrhosis after endoscopic therapy remains controversial. This study aimed to evaluate the effect of PPI on gastroesophageal varices in patients with cirrhosis after endoscopic therapy, including variceal bleeding and adverse events.

\section{Methods}

Between May 2017 and June 2019, cirrhotic patients with gastroesophageal varices confirmed by endoscopy were considered for enrollment in this study. Eligible subjects were randomized into two groups: one group received PPI for 14 days and the other group did not undergo PPI treatment. Patients were followed up for 8 weeks.

\section{Results}

During the follow-up period, three patients $(3 / 53,5.66 \%)$ in the PPI group experienced variceal bleeding on day 9,16 , and 25 after endoscopic therapy, including one patient with primary prophylaxis and two with acute bleeding. In the non-PPI group, three patients $(3 / 56,5.66 \%)$ suffered from variceal bleeding on day 7,42 , and 56 after endoscopic therapy, including two patients with secondary prophylaxis and one with acute bleeding ( $P>0.99)$. The rate of adverse events was similar between the two groups ( $38 \%$ vs. $28 \%$, $P=0.30$ ). Furthermore, the average hospitalization expense of patients in the PPI group was higher than that of patients in the non-PPI group ( $\$ 2305$ vs. $\$ 3096, P<0.001)$.

\section{Conclusions}

PPI does not appear to reduce variceal bleeding and adverse events in patients with cirrhosis after endoscopic therapy.

Trial registration: This trial was registered with ClinicalTrials.gov (NCT 03175731, 05/06/2017).

\section{Background}

Gastroesophageal varices (GEVs) are one of the most common complications of cirrhosis. GEVs present in $30-40 \%$ cases of compensated cirrhosis, and up to $48-85 \%$ cases of decompensated cirrhosis ${ }^{[1]}$. As the disease progresses, GEVs develop into life-threatening variceal bleeding. According to previous reports, the annual incidence of variceal bleeding is $10-15 \%$, with a six-week mortality rate of approximately $20 \%{ }^{[2,3]}$. Furthermore, without endoscopic therapy, rebleeding occurs at a rate of $60 \%$ after initial bleeding, with a mortality rate up to $33 \%\left[{ }^{[4]}\right.$. 
Currently, conventional management of GEVs include endoscopic therapy (such as endoscopic variceal ligation [EVL] and endoscopic tissue adhesive [ETA]), and pharmacologic therapy (including the use of vasoconstrictors) ${ }^{[5-7]}$. However, the effects of proton pump inhibitor (PPI) on GEVs in patients with cirrhosis after endoscopic therapy remain controversial. PPI has been confirmed effective in treating nonvariceal upper gastrointestinal bleeding by stimulating platelet aggregation and fibrin clot formation and inactivating pepsin by suppressing the gastric acid secretion ${ }^{[8-10]}$. However, it is controversial if such effects can be extended for GEVs in patients with cirrhosis, in which the pathology and location of lesions differ significantly. Moreover, there is no direct evidence showing that PPI can directly affect portal pressure.

Previous retrospective studies have shown that PPI could reduce bleeding risk after prophylactic EVL ${ }^{[11}$, ${ }^{12}$. In a retrospective study by Jang et al., it was suggested that PPI may delay rebleeding in patients with cirrhosis after therapeutic endoscopy $(n=16)^{[13]}$. However, in several studies, no significant differences were observed in the rates of bleeding and mortality after endoscopic intervention between patients who received PPI and patients who did not ${ }^{[14-16]}$. According to the Chinese Medical Association practice guidance, PPI has been suggested as an adjuvant treatment after endoscopic therapy for improving hemostasis and reducing early rebleeding after endoscopic therapy ${ }^{[17]}$. However, it should be noted that the updated UK guidelines do not recommend the use of PPI for cirrhosis with GEVs after endoscopic therapy (prophylactic or therapeutic), unless patients present with peptic ulcer disease ${ }^{[18]}$. Thus, there is insufficient evidence to demonstrate the effects of PPI on GEVs in patients with cirrhosis after endoscopic therapy. However, as an effective gastric acid inhibitor, PPI is commonly used for GEVs in patients with cirrhosis, especially in cases with acute variceal bleeding ${ }^{[19]}$. A retrospective study showed that more than $80.2 \%$ of patients with cirrhosis and GEVs received acid suppression treatment ${ }^{[20]}$. To avoid potential abuse and use PPI reasonably, this study aimed to evaluate the effects of PPI on GEVs in patients with cirrhosis, including variceal bleeding and adverse events after endoscopic therapy.

\section{Patients And Methods}

\section{Patients selection}

Between May 2017 and June 2019, cirrhotic patients with GEVs were considered for enrollment in this study. The following inclusion criteria were applied: (1) age $\geq 18$ years; (2) cirrhosis was diagnosed based on clinical, laboratory, and radiological parameters and/or liver biopsy; (3) GEVs were diagnosed by endoscopy. The exclusion criteria were as follows: (1) acute gastrointestinal bleeding requiring emergency surgery; (2) acid-related disease, such as peptic ulcer disease or gastroesophageal reflux diseases; (3) hepatocellular carcinoma or other malignant tumor; (4) history of surgery of the esophagus, stomach or liver; (5) Child-Pugh grade $\mathrm{C}$ disease that cannot be improved to grade A or B; (6) preparing to be pregnant, pregnant, or breast feeding; (7) PPI allergies; and 8) missing informed consent.

\section{Randomization and masking}


Randomization was performed after GEVs were confirmed by endoscopy. Eligible patients were randomized into PPI and non-PPI groups in a 1:1 ratio using a computer-generated list of random numbers. The numbers were written on papers placed in sealed and opaque envelopes by an independent research assistant. After confirmation of GEVs by endoscopy and inclusion in this study, one envelope was opened. The expert endoscopists were blinded to the randomization and patients data.

\section{Procedures}

An initial endoscopy was performed with endoscopic findings classified according to the grading system outlined in the guidelines released by Chinese Medical Association ${ }^{[17]}$. The grades $(G)$ of esophageal varices were classified into three groups: (1) G1 lesions were straight or slightly curved without red color signs; (2) G2 lesions were straight or slightly curved with red color signs, or serpentine with no color signs; (3) G3 lesions were serpentine with red color signs, beaded and nodular, or tumor-shaped with/without red color signs.

After an initial endoscopy, endoscopic therapy was undertaken according to updated UK guidelines (Fig. 1) ${ }^{[18]}$. EVL was conducted for all patients with esophageal varices, starting at the gastroesophageal junction and progressing proximally every $1-2 \mathrm{~cm}$ in an upward spiral using a six-shooter multi-band ligator (Cook Medical, MBL-6-F, Winston-Salem, NC, USA). ETA was performed in patients presenting with gastric varices in the "sandwich" configuration. The needle (Olympus, NM-200L-0521, Tokyo, Japan) was flushed with a $0.9 \%$ sodium chloride solution, followed by a tissue adhesive (FAL, Fuaile medical adhesive, Beijing, China) and then $0.9 \%$ sodium chloride solution again. All participants enrolled in this study were banded every 2 weeks; however, patients who suffered from rebleeding received rescue EVL/ETA as soon as possible. Endoscopic therapy was performed by three expert endoscopists with more than 10 years of relevant experience.

After endoscopic therapy, eligible patients were randomly assigned to the PPI group (received pantoprazole $40 \mathrm{mg} /$ day intravenously/orally for 14 days) or the non-PPI group (did not receive PPI treatment).

\section{Outcomes and follow-up}

The primary endpoint was variceal bleeding, which was defined as hematemesis or melena from endoscopically proven GEVs, in the absence of any other lesion that might explain the bleeding. The secondary endpoint was adverse events, caused by endoscopic therapy and occurring within 8 weeks after endoscopic therapy, including chest discomfort, dysphagia, and fever. Follow-up was undertaken for 8 weeks after endoscopic therapy.

\section{Sample size calculation and statistical analysis}

To calculate the sample size, the overall variceal bleeding rate after endoscopic therapy was chosen as the primary outcome. According to published data ${ }^{[21]}$, and assuming a $22 \%$ difference in the rate of variceal bleeding between the non-PPI group (27\%) and the PPI group (5\%), at least 46 patients were 
required in each group to provide $90 \%$ confidence in the results, with the upper limit of the one-sided $95 \%$ confidence interval ( $a=0.05, \beta=0.10)$. Moreover, assuming a flow off rate of $10 \%$, at least 100 patients were required in this study.

Statistical analysis was based on the intention-to-treat principle. Quantitative variables were compared using Student's $t$-test or Mann-Whitney U-test, and the $\chi^{2}$ test or Fisher's exact test was used to compare qualitative variables. The cumulative rate of bleeding was calculated using the Kaplan-Meier method, and log-rank tests were performed for comparison of differences. $P$ values $<0.05$ were considered statistically significant. Statistical analyses were performed using SPSS software (version 22.0, Chicago, IL, USA) and GraphPad Prism software (version 7.0, San Diego, CA, USA).

\section{Results}

\section{Patient flow and baseline characteristics}

A total of 209 patients with cirrhosis and GEVs were screened. After exclusion, 106 subjects were enrolled and randomized into this study (with 53 subjects in each group). In the PPI group, there were 12 primary prophylactic patients, 32 secondary prophylactic patients, and nine active bleeding patients; in the nonPPI group, there were 14 primary prophylactic patients, 30 secondary prophylactic patients, and nine active variceal bleeding patients. One patient in the PPI group withdrew from this study for interrupting PPI treatment, and four patients in the non-PPI group withdrew because of chest discomfort or nausea after endoscopic therapy. Four patients in the PPI groupand three in the non-PPI group were lost to followup (Fig. 2).

As shown in Table 1, the baseline characteristics of patients in two groups were comparable. Most patients were male in both groups. The numbers of males in the PPI group and the non-PPI group were 36 $(68 \%)$ and $38(72 \%)$, respectively. Ages were $53.6 \pm 10.0$ years in the PPI group and $54.2 \pm 10.6$ years in the non-PPI group. The most common etiology of cirrhosis was HBV infection in both groups. The endoscopic characteristics of the two groups were comparable as shown in Table 1. 
Table 1

Baseline characteristics of two groups

\begin{tabular}{|c|c|c|c|}
\hline Characteristic & Non-PPI group $(\mathrm{N}=53)$ & PPI group ( $N=53)$ & $P$ value \\
\hline Age (years) & $54.2 \pm 10.6$ & $53.6 \pm 10.0$ & 0.76 \\
\hline Sex (female: male) & $15: 38$ & $17: 36$ & 0.67 \\
\hline $\begin{array}{l}\text { Primary: Acute: } \\
\text { Secondary }\end{array}$ & & & 0.90 \\
\hline Primary prophylaxis & $14(26 \%)$ & $12(23 \%)$ & \\
\hline Acute bleeding & $9(17 \%)$ & $9(17 \%)$ & \\
\hline Secondary prophylaxis & $30(57 \%)$ & $32(60 \%)$ & \\
\hline Etiology of cirrhosis & & & 0.30 \\
\hline HBV & $31(58 \%)$ & $27(51 \%)$ & \\
\hline $\mathrm{HCV}$ & $0(0 \%)$ & $2(4 \%)$ & \\
\hline Alcohol & $9(17 \%)$ & $9(17 \%)$ & \\
\hline Autoimmune & $2(4 \%)$ & $0(0 \%)$ & \\
\hline Others & $11(21 \%)$ & $15(28 \%)$ & \\
\hline Child-Pugh degree & & & 0.59 \\
\hline Child-Pugh A & $44(83 \%)$ & $46(87 \%)$ & \\
\hline Child-Pugh B & $9(17 \%)$ & $7(13 \%)$ & \\
\hline PVT & $14(26 \%)$ & $17(32 \%)$ & 0.81 \\
\hline Ascites & $26(49 \%)$ & $23(43 \%)$ & 0.56 \\
\hline Encephalopathy & $0(0 \%)$ & $1(2 \%)$ & 1.00 \\
\hline Albumin (g/L) & $38.27 \pm 4.38$ & $39.14 \pm 4.72$ & 0.33 \\
\hline Prothrombin activity (\%) & $72 \pm 14$ & $71 \pm 14$ & 0.74 \\
\hline Creatinine (mg/dL) & $64 \pm 14$ & $60 \pm 12$ & 0.16 \\
\hline Hemoglobin(g/L) & $92.00(80.50,120.00)$ & $96.00(77.50,125.50)$ & 0.72 \\
\hline Platelet(*10^9/L) & $78.00(56.00,149.50)$ & $101.00(62.00,154.50)$ & 0.26 \\
\hline TBIL (mg/dL) & $17.80(12.85,24.00)$ & $18.30(12.20,24.60)$ & 0.96 \\
\hline
\end{tabular}

PPIs, proton pump inhibitors; $\mathrm{HBV}$, hepatitis $\mathrm{B}$ virus; $\mathrm{HCV}$, hepatitis $\mathrm{C}$ virus; $\mathrm{PVT}$, portal vein thrombosis; TBIL, Total bilirubin; PT, Prothrombin time; INR, international Normalized Ratio; MELD, model for endstage liver disease; PHG, portal hypertensive gastropathy. 


\begin{tabular}{|c|c|c|c|}
\hline Characteristic & Non-PPI group $(\mathrm{N}=53)$ & PPI group $(N=53)$ & $P$ value \\
\hline PT (sec) & $13.70(12.30,15.15)$ & $13.80(12.35,15.75)$ & 0.77 \\
\hline INR & $1.24(1.14,1.38)$ & $1.26(1.13,1.42)$ & 0.87 \\
\hline MELD score & $9(8,11)$ & $9(8,11)$ & 0.97 \\
\hline Child-Pugh score & $6(5,6)$ & $6(5,6)$ & 0.48 \\
\hline Esophageal varices & $53(100 \%)$ & $53(100 \%)$ & 0.08 \\
\hline G1 & $7(13 \%)$ & $1(2 \%)$ & \\
\hline G2 & $21(40 \%)$ & $26(49 \%)$ & \\
\hline G3 & $25(47 \%)$ & $26(49 \%)$ & \\
\hline Gastric varices & $27(51 \%)$ & $30(57 \%)$ & 0.56 \\
\hline Red color sign & $43(81 \%)$ & $43(81 \%)$ & 1.00 \\
\hline PHG & $28(53 \%)$ & $18(34 \%)$ & 0.05 \\
\hline $\begin{array}{l}\text { Number of esophageal } \\
\text { varices }\end{array}$ & $3(2,4)$ & $3(3,4)$ & 0.22 \\
\hline Number of bands & $6(6,7)$ & $6(6,11)$ & 0.07 \\
\hline
\end{tabular}

\section{Variceal bleeding events after endoscopic therapy}

No bleeding events were observed within the first 48 hours after endoscopic therapy in the two groups (Table 2). During the 8-week follow-up period, three patients $(3 / 53,5.66 \%)$ in the PPI group suffered variceal bleeding on the 9th, 16th, and 25th day after endoscopic therapy; these included one primary prophylactic patient and two acute bleeding patients. Three patients $(3 / 53,5.66 \%)$ in the non-PPI group experienced variceal bleeding on the 7th, 42nd, and 56th day after endoscopic therapy; these included two secondary prophylactic patients and one acute bleeding patient. No significant differences were observed in total bleeding events between the two groups ( $P>0.99$, Fig. 3$)$. 
Table 2

Outcomes of two groups

\begin{tabular}{|c|c|c|c|}
\hline Outcomes & Non-PPI group & PPI group & $P$ value \\
\hline Early bleeding (within 48h) & $0(0 \%)$ & $0(0 \%)$ & 1.00 \\
\hline Total bleeding (within 8w) & $3(3 / 53,5.66 \%)$ & $3(3 / 53,5.66 \%)$ & 1.00 \\
\hline Acute bleeding & $1(1 / 9,11.11 \%)$ & $2(2 / 9,22.22 \%)$ & 0.59 \\
\hline Primary prophylaxis & $0(0 / 14,0.00 \%)$ & $1(1 / 12,8.33 \%)$ & 0.28 \\
\hline Secondary prophylaxis & $2(2 / 30,6.67 \%)$ & $0(0 / 32,0.00 \%)$ & 0.14 \\
\hline Mortality (Acute VH) & $0(0 \%)$ & $1(1 / 9,11.11 \%)$ & 0.32 \\
\hline Blood transfusion (units) & $0(0,0)$ & $0(0,1.5)$ & 0.65 \\
\hline Total hospital stays (days) & $8(7,11)$ & $10(8,11)$ & 0.02 \\
\hline Cost of hospitalization (Dollars) & $2305(1886,3015)$ & $3096(2323,4156)$ & $<0.001$ \\
\hline \multicolumn{4}{|l|}{ Adverse event } \\
\hline Total adverse events & $20(38 \%)$ & $15(28 \%)$ & 0.30 \\
\hline Chest discomfort & $14(26 \%)$ & $11(21 \%)$ & 0.72 \\
\hline Abdominal pain & $3(6 \%)$ & $0(0 \%)$ & 0.11 \\
\hline Nausea or vomit & $9(17 \%)$ & $5(9 \%)$ & 0.21 \\
\hline Dysphagia & $4(8 \%)$ & $4(8 \%)$ & 1.00 \\
\hline Fever & $0(0 \%)$ & $1(2 \%)$ & 1.00 \\
\hline Weak & $0(0 \%)$ & $1(2 \%)$ & 1.00 \\
\hline Weight loss & $0(0 \%)$ & $1(2 \%)$ & 1.00 \\
\hline \multicolumn{4}{|c|}{$\begin{array}{l}\text { The non-normal distributed measurement dates were presented as Medians (IQR, (P25, P75)). } \\
\text { Enumeration data are shown in number (percentage). PPIs, proton pump inhibitors; EVL, endoscopic } \\
\text { variceal ligation; ETA, endoscopic tissue adhesive. }\end{array}$} \\
\hline
\end{tabular}

Among these six rebleeding patients, four patients bled from esophageal varices, one from fundic varices, and one rebled from post-ligation ulcers. Although bleeding events of five patients were managed effectively with pharmaceutical treatments and/or endoscopic interventions, one patient with acute variceal bleeding in the PPI group died of rebleeding on the 16th day after endoscopic therapy $(P=0.32)$.

\section{Adverse events after endoscopic therapy}

As shown in Table 2, adverse events were experienced in a total of 20 patients (38\%) in the non-PPI group, and 15 patients $(28 \%)$ in the PPI group $(P=0.30)$. The most common adverse events in both groups were chest discomfort, nausea or vomiting, and dysphagia, with no statistically significant differences between 
groups $(P=0.30)$. However, it should be noted that fever, weakness, and weight loss (approximately 9 kilograms) was observed in three patients in the PPI group, whereas similar symptoms were not experienced by any patient in the non-PPI group. All adverse events disappeared within 8 weeks after endoscopic therapy.

\section{Hospitalization expense and blood transfusion}

The total hospital expense per patient in the PPI group vs non-PPI group was \$3096 (IQR 2323, 4156) versus $\$ 2305$ (IQR 1886, 3015) (1 Chinese Yuan = 0.1421 US dollar), and this difference was statistically significant $(P<0.001)$. The requirement for blood transfusions was similar between the two groups $(P=$ 0.65).

\section{Discussion}

The findings of this study indicated that PPI may not reduce variceal bleeding in patients with cirrhosis after endoscopic therapy. The rate of adverse events was also similar among patients treated with or without PPI. Furthermore, PPI administration may be related to higher hospital costs.

These findings are consistent with data presented in previous studies, thereby demonstrating that there was no significant difference in the incidence of variceal bleeding and mortality (within 6 weeks) after prophylactic or therapeutic endoscopic intervention ${ }^{[14,15]}$. In addition, in several studies, it has been demonstrated that PPI increased the risk of bacterial infection in patients with cirrhosis ${ }^{[22,23]}$. A previous prospective study has revealed that the incidence of hepatic encephalopathy was higher (64\% vs. 25\%) and the overall survival rate was lower $(41 \%$ vs. $81 \%)$ in patients with cirrhosis who received PPI treatment ${ }^{[24]}$.

Although a retrospective study of 505 patients showed that the incidence of post-EVL bleeding was lower in the PPI group than in the non-PPI group $(0.84 \%[3 / 359] \text { vs. } 7.53 \%[11 / 146])^{[12]}$, a retrospective, nonrandomized study may be associated with a high risk of bias. In another small scale $(\mathrm{N}=16)$ retrospective study by Jang et al., cirrhotic patients with variceal bleeding who received PPI trestment were shown to have longer bleeding intervals and fewer bleeding events after endoscopic therapy ${ }^{[13]}$; however, these findings were not observed in our study. A previously reported randomized controlled trial revealed that PPI treatment reduced the risk of treatment failure (bleeding or serious complications) after $\mathrm{EVL}^{[21]}$, but the rates of bleeding and serious complications were not analyzed separately and the sample size was small $(n=43)$.

There are several possible explanations for why PPI may not reduce the incidence of variceal bleeding in patients with cirrhosis after endoscopic therapy. First, as mentioned previously, there are significant differences in the pathology and location of GEVs and nonvariceal upper gastrointestinal bleeding. Key management strategies for GEVs are to stop the bleeding by endoscopic intervention and reduce portal pressure using medication. Second, the ulcers caused by EVL were iatrogenic, which are highly selflimiting; accordingly, acid suppression treatment may be unnecessary. In addition, GEVs were not an 
indication in the prescription of PPI. Unnecessary administration of PPI may cause an additional economic burden for these patients.

What should be noticed is that the rate of variceal bleeding in this study was lower than expected ${ }^{[12,21]}$. There are several possible reasons to explain this low bleeding rate: first, all variceal bleeding events in this study were observed after endoscopic therapy which could reduce the occurrence of variceal bleeding. Furthermore, patients with extremely poor liver function usually received pharmacotherapy before endoscopic therapy to improve liver function and decrease the failure risk of endoscopic therapy.

In addition, the average hospitalization expense of patients in the PPI group was higher than that of patients in the non-PPI group. This may have resulted from the following reasons. First, patients in the PPI group received more PPI treatments during 14 days compared with patients in the non-PPI group (including oral administration after discharge). Second, the length of hospitalization of patients in the PPI group was longer as shown in Table 2, which might be associated with adverse events in several patients in the PPI group. In the PPI group, fever, weakness, and weight loss was observed in three patients, whereas similar symptoms were not observed in any of the patients in the non-PPI group. Although differences were not statistically significant, it may have resuled from the low incidence of those adverse events and the small sample size in this study. Nonetheless, in previous studies, it was shown that PPI

treatment was related to adverse events and poor prognosis of patients with cirrhosis ${ }^{[25,26]}$. In a retrospective study by Li et al., it was demonstrated that PPI was associated with an increased risk of bacterial infections and hepatic decompensation in 11526 patients with hepatitis $C$ virus infection [27]. Although these effects are not entirely clear, clinicians should avoid the abuse of PPI, especially for patients with cirrhosis.

This study has several limitations. First, this study was not blinded to patients, which may cause bias. Second, the use of prophylactic antibiotics was not standardized in the two groups. Although the types of antibiotics were not identical, no significant differences were observed between the two groups with regard to the total number of patients treated with antibiotics. Lastly, this prospective randomized controlled trial was a single-center study with a small sample size. In the future, more large-scale randomized controlled trials should be conducted to confirm these findings in different regions and populations.

\section{Conclusion}

The results of this study suggest that PPI does not reduce the occurrence of variceal bleeding and adverse events in patients with cirrhosis after endoscopic therapy. In addition, the average hospitalization expense of the PPI group was higher than that of the non-PPI group.

\section{Declarations}

Ethics approval and consent to participate 
This study was approved by the Ethics Committee of Qilu Hospital of Shandong University in accordance with the Declaration of Helsinki (No. 2017037). Written informed consent was obtained from each participant.

\section{Consent for publication}

The patients have informed consent to the submission of the report to the journal.

\section{Availability of data and materials}

Upon reasonable request, the data for this study are available from the corresponding author.

\section{Competing interests}

The authors have no conflicts of interest to declare.

\section{Funding}

None of funding were used for the work of this manuscript.

\section{Authors' contributions}

$Y G$ and $X C$ conceived and designed the project. $X C$, Ting $Z$ and $X S$ collected the data. $X C$, Tao $Z$, and $Y L$ analyzed and interpreted the data. $X C$ and Tao $Z$ drafted the manuscript. $Y G$ and $Y L$ revised the manuscript. BC, NZ and XL contributed to technical support and study supervision. All authors read and approved the final manuscript.

\section{Acknowledgments}

The authors would like to thank MogoEdit (www.mogoedit.com) for English language editing.

\section{Abbreviations}

EVL: Endoscopic variceal ligation

ETA: Endoscopic tissue adhesive

GEVs: Gastroesophageal varices

PPI: Proton pump inhibitor.

\section{References}

1. Seo YS. Prevention and management of gastroesophageal varices. Clin Mol Hepatol. 2018;24:20-42. https://doi.org/10.3350/cmh.2017.0064 
2. North Italian Endoscopic Club for the Study and Treatment of Esophageal Varices. Prediction of the first variceal hemorrhage in patients with cirrhosis of the liver and esophageal varices. A prospective multicenter study. N Engl J Med. 1988;319:983-9.

https://www.nejm.org/doi/full/10.1056/NEJM198810133191505

3. Amitrano L, Guardascione MA, Manguso F, Bennato R, Bove A, DeNucci C, et al. The effectiveness of current acute variceal bleed treatments in unselected cirrhotic patients: refining short-term prognosis and risk factors. Am J Gastroenterol. 2012;107:1872-8. https://doi.org/10.1038/ajg.2012.313

4. Bari K, Garcia-Tsao G.Treatment of portal hypertension. World J Gastroentero. 2012;18:1166-75. https://doi.org/10.3748/wjg.v18.i11.1166

5. Fukui H, Saito H, Ueno Y, Uto H, Obara K, Sakaida I, et al. Evidence-based clinical practice guidelines for liver cirrhosis 2015. J Gastroenterol. 2016;51:629-50. https://doi.org/10.1007/s00535-016-1216-y

6. Garcia-Tsao G, Abraldes JG, Berzigotti A, Bosch J. Portal hypertensive bleeding in cirrhosis: Risk stratification, diagnosis, and management: 2016 practice guidance by the American Association for the study of liver diseases. Hepatology. 2017;65:310-35. https://doi.org/10.1002/hep.28906

7. Boregowda U, Umapathy C, Halim N, Desai M, Nanjappa A, Arekapudi S, et al. Update on the management of gastrointestinal varices. World J Gastrointest Pharmacol Ther. 2019;10:1-21. https://doi.org/10.4292/wjgpt.v10.i1.1

8. Chaimoff C, Creter D, Djaldetti M. The effect of $\mathrm{pH}$ on platelet and coagulation factor activities. Am J Surg. 1978;136:257-9. https://doi.org/10.1016/0002-9610(78)90241-6

9. Chinese Journal of Internal Medicine; National Medical Journal of China; Chinese Journal of Digestion; Chinese Journal of Digestive Endoscopy; Chinese Digestive Endoscopist Association. [Guidelines for the diagnosis and treatment of acute non-variceal upper gastrointestinal bleeding (2018, Hangzhou)]. Zhonghua nei ke za zhi. 2019;58:173-80.

https://doi.org/10.3760/cma.j.issn.0578-1426.2019.03.005

10. Sung JJ, Chiu PW, Chan FKL, Lau JY, Goh KL, Ho LH, et al. Asia-Pacific working group consensus on non-variceal upper gastrointestinal bleeding: an update 2018. Gut.2018;67:1757-68.

https://doi.org/10.1136/gutjnl-2018-316276

11. Kang SH, Yim HJ, Kim SY, Suh SJ, Hyun JJ, Jung SW, et al. Proton Pump Inhibitor Therapy Is Associated With Reduction of Early Bleeding Risk After Prophylactic Endoscopic Variceal Band Ligation: A Retrospective Cohort Study. Medicine.2016;95:e2903. https://doi.org/10.1097/md.0000000000002903

12. Zhu J, Qi X, Yu H, Su C, Guo X. Acid suppression in patients treated with endoscopic therapy for the management of gastroesophageal varices: a systematic review and meta-analysis. Expert Rev 
Gastroent. 2018;12:617-24. https://doi.org/10.1080/17474124.2018.1456918

13. Jang WS, Shin HP, Lee JI, Joo KR, Cha JM, Jeon JW, et al. Proton pump inhibitor administration delays rebleeding after endoscopic gastric variceal obturation. World J Gastroentero. 2014;20:1712731. https://doi.org/10.3748/wjg.v20.i45.17127

14. Garcia-Saenz-de-Sicilia M, Sanchez-Avila F, Chavez-Tapia NC, Lopez-Arce G, Garcia-Osogobio S, RuizCordero R, et al. PPIs are not associated with a lower incidence of portal-hypertension-related bleeding in cirrhosis. World J Gastroentero. 2010;16:5869-73. https://doi.org/10.3748/wjg.v16.i46.5869

15. Lo GH, Perng DS, Chang CY, Tai CM, Wang HM, Lin HC. Controlled trial of ligation plus vasoconstrictor versus proton pump inhibitor in the control of acute esophageal variceal bleeding. $J$ Gastroen Hepatol. 2013;28:684-9. https://doi.org/10.1111/jgh.12107

16. Shaheen NJ, Stuart E, Schmitz SM, Mitchell KL, Fried MW, Zacks S, et al. Pantoprazole reduces the size of postbanding ulcers after variceal band ligation: a randomized, controlled trial. Hepatology. 2005;41:588-94. https://doi.org/10.1002/hep.20593

17. Chinese Society of Hepatology, Chinese Medical Association; Chinese Society of Gastroenterology, Chinese Medical Association; Chinese Society of Endoscopy, Chinese Medical Association. Guidelines for the diagnosis and treatment of esophageal and gastric variceal bleeding in cirrhotic portal hypertension. J Clin Hepatol. 2016;32:203-19. http://dx.chinadoi.cn/10.3969/j.issn.10015256.2016.02.002

18. Tripathi D, Stanley AJ, Hayes PC, Patch D, Millson C, Mehrzad M, et al. U.K. guidelines on the management of variceal haemorrhage in cirrhotic patients. Gut. 2015;64:1680-1704. https://doi.org/10.1136/gutjnl-2015-309262

19. Alaniz C, Mohammad RA, Welage LS. Continuous infusion of pantoprazole with octreotide does not improve management of variceal hemorrhage. Pharmacotherapy. 2009;29:248-54. https://doi.org/10.1592/phco.29.3.248

20. Wu CK, Liang CM, Hsu CN, Hung TH, Yuan LT, Nguang SH, et al. The Role of Adjuvant Acid Suppression on the Outcomes of Bleeding Esophageal Varices after Endoscopic Variceal Ligation. PloS one. 2017;12:e0169884. https://doi.org/10.1371/journal.pone.0169884

21. Hidaka H, Nakazawa T, Wang G, Kokubu S, Minamino T, Takada J, et al. Long-term administration of PPI reduces treatment failures after esophageal variceal band ligation: a randomized, controlled trial. J gastroenterol. 2012;47:118-26. https://doi.org/10.1007/s00535-011-0472-0

22. Dam G, Vilstrup H, Andersen PK, Bossen L, Watson H, Jepsen P. Effect of proton pump inhibitors on the risk and prognosis of infections in patients with cirrhosis and ascites. Liver int. 2019;39:514-21. 
23. Elzouki AN, Neffati N, Rasoul FA, Abdallah A, Othman M, Waness A. Increased Risk of Spontaneous Bacterial Peritonitis in Cirrhotic Patients Using Proton Pump Inhibitors. GE Portuguese journal of gastroenterology. 2019;26:83-9. https://doi.org/10.1159/000487963

24. Nardelli S, Gioia S, Ridola L, Farcomeni A, Merli M, Riggio O. Proton Pump Inhibitors Are Associated With Minimal and Overt Hepatic Encephalopathy and Increased Mortality in Patients With Cirrhosis. Hepatology. 2019;70:640-9. https://doi.org/10.1002/hep.30304

25. Dultz G, Piiper A, Zeuzem S, Kronenberger B, Waidmann O. Proton pump inhibitor treatment is associated with the severity of liver disease and increased mortality in patients with cirrhosis. Aliment Pharm Ther. 2015;41:459-66. https://doi.org/10.1111/apt.13061

26. De Roza MA, Kai L, Kam JW, Chan YH, Kwek A, Ang TL, et al. Proton pump inhibitor use increases mortality and hepatic decompensation in liver cirrhosis. World J Gastroentero. 2019;25:4933-44. https://doi.org/10.3748/wjg.v25.i33.4933

27. Li DK, Yan P, Abou-Samra AB, Chung RT, Butt AA. Proton pump inhibitors are associated with accelerated development of cirrhosis, hepatic decompensation and hepatocellular carcinoma in noncirrhotic patients with chronic hepatitis $\mathrm{C}$ infection: results from ERCHIVES. Aliment Pharm Ther. 2018;47:246-58. https://doi.org/10.1111/apt.14391

\section{Figures}

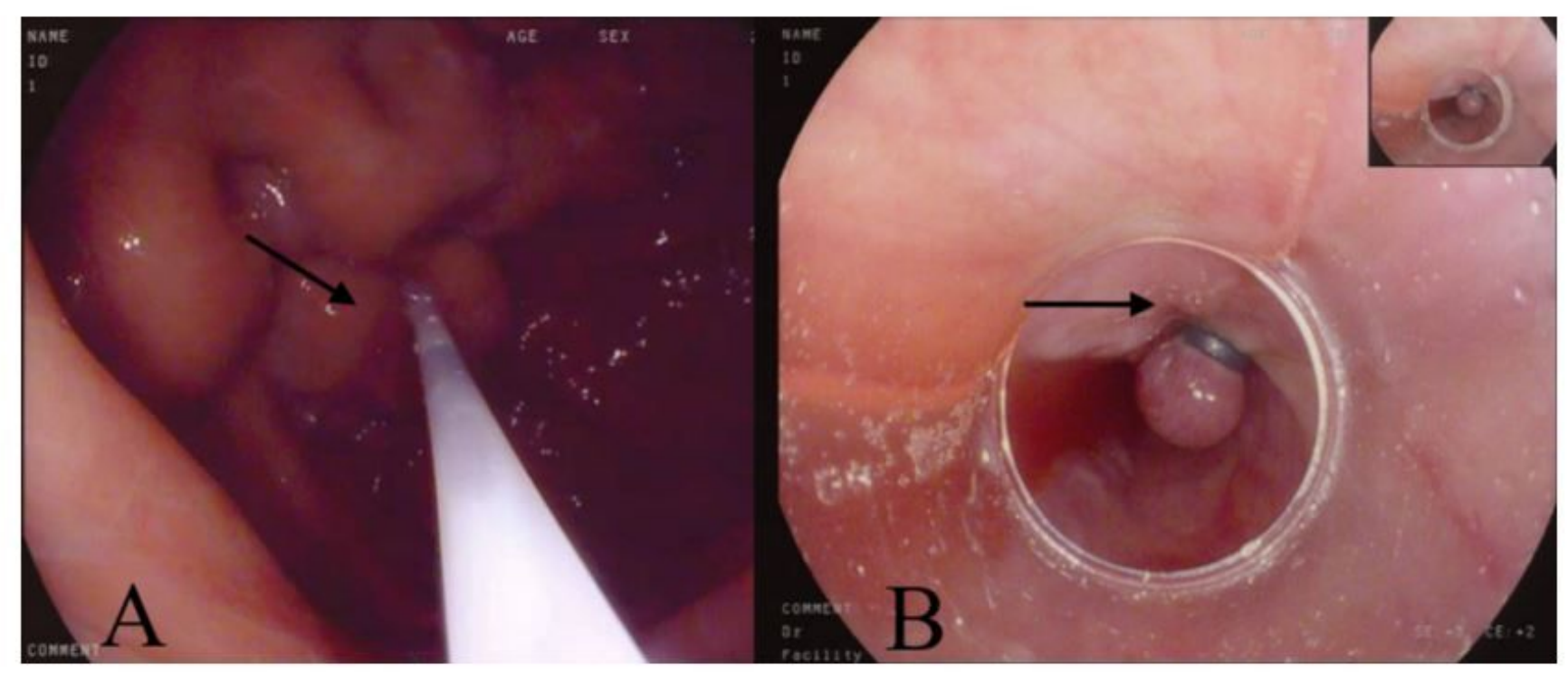


Figure 1

A. Endoscopic tissue adhesive; B. Endoscopic variceal ligation

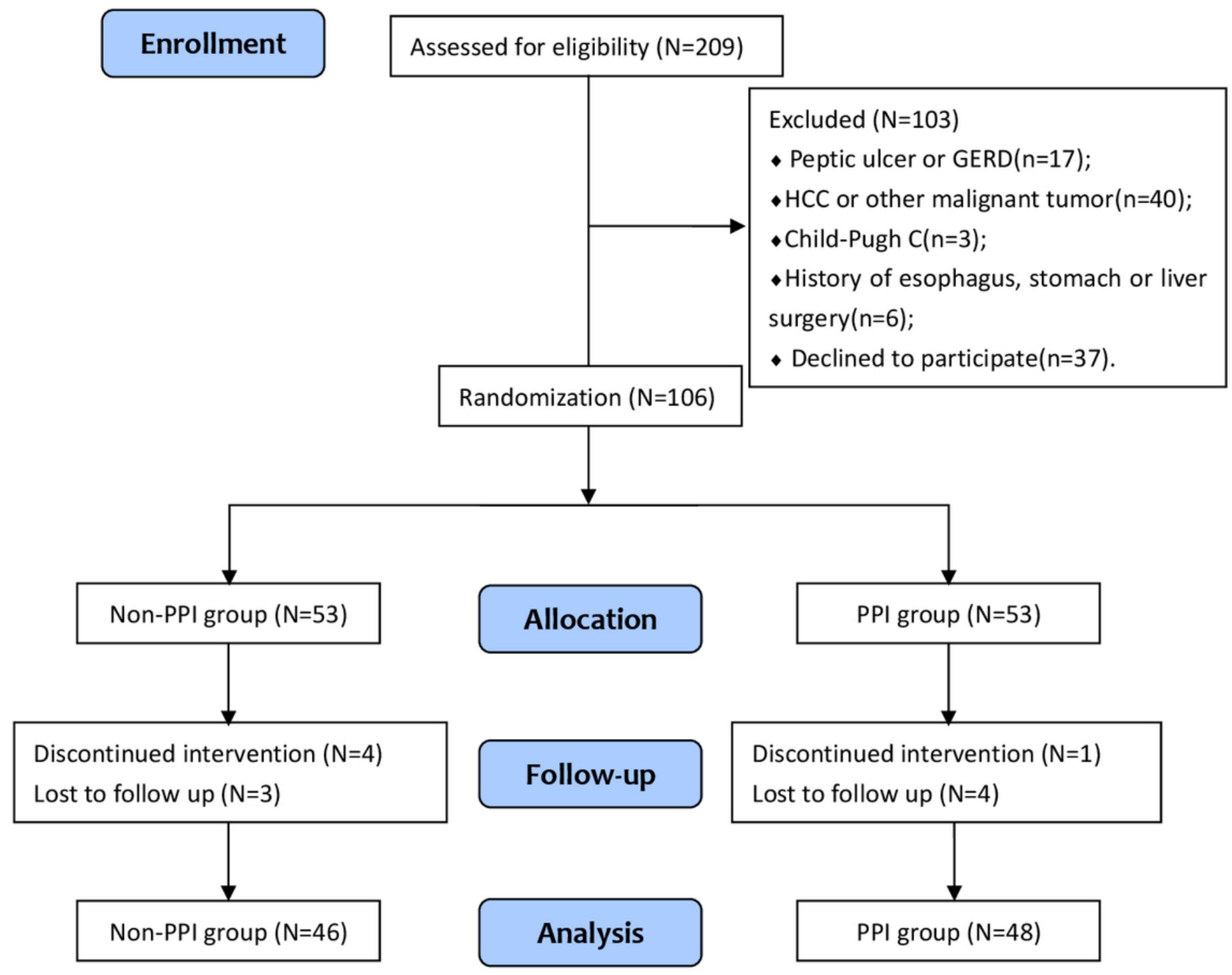

Figure 2

Patients flow diagram GERD: Gastroesophageal reflux diseases; HCC: Hepatocellular carcinoma 


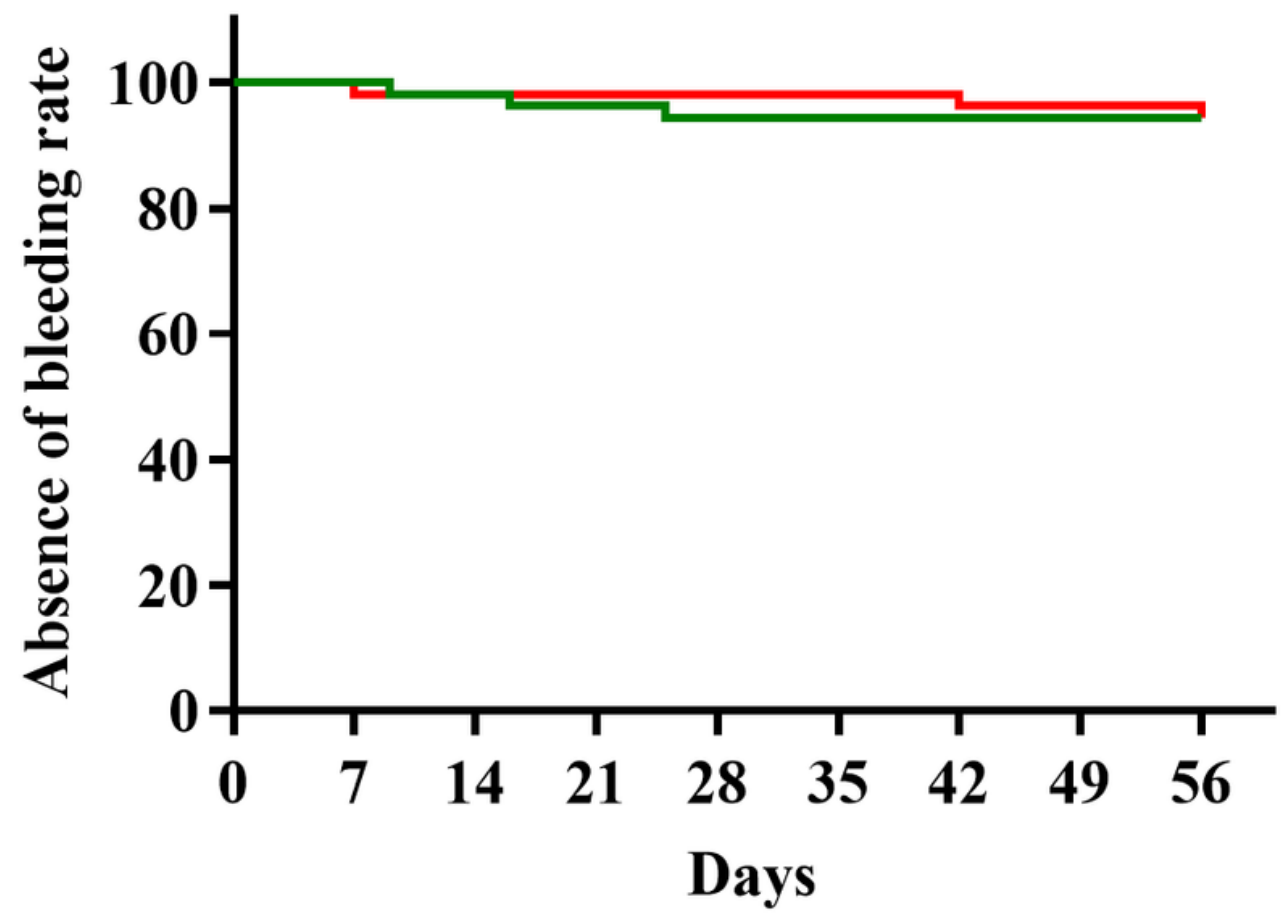

- non-PPI

- PPI

Number of non-bleeding patients

$\begin{array}{llllllllll}\text { Non-PPI } & 53 & 52 & 52 & 52 & 52 & 52 & 51 & 51 & 50\end{array}$

$\begin{array}{llllllllll}\text { PPI } & 53 & 53 & 52 & 51 & 50 & 50 & 50 & 50 & 50\end{array}$

Figure 3

Absence of bleeding rate in the PPI group and the non-PPI group 